\title{
International Journal of Stem Cell Research and Transplantation (IJST) ISSN 2328-3548
}

\section{The Use of Spermatogonial Stem Cells In Cancer-Induced Infertility}

Sá, R. ${ }^{1, *}$, Sousa, M. ${ }^{1,2}$, Oliveira, P.F. ${ }^{1,3}$, Alves, M.G. ${ }^{3, *}$

${ }^{1}$ Department of Microscopy, Laboratory of Cell Biology, Institute of Biomedical Sciences Abel Salazar (ICBAS), Unit for Multidisciplinary Research in Biomedicine (UMIB), University of Porto, Portugal.

${ }^{2}$ Centre for Reproductive Genetics Professor. Alberto Barros, Portugal.

${ }^{3}$ CICS-UBI, Health Sciences Research Centre, University of Beira Interior, Portugal.

\section{*Corresponding Author:}

Rosália Sá,

Institute of Biomedical Sciences Abel Salazar, University of Porto, Rua de Jorge Viterbo Ferreira, 228, 4050-313 Porto, Portugal.

Email: rmsa@icbas.up.pt

Marco G. Alves,

University of Beira Interior, Av. Infante D. Henrique, 6201-506 Covilhã, Portugal.

E-mail: alvesmarc@gmail.com

Received: June 01, 2015

Published: June 05, 2015

Citation: Sá, R, Sousa, M, Oliveira P.F, Alves M.G (2015) The Use of Spermatogonial Stem Cells In Cancer-Induced Infertility. Int I Stem Cell Res Transplant 03(2e) 1-2. doi: http://dx.doi.org/10.19070/2328-3548$150005 \mathrm{e}$

Copyright: Sá, R, Alves M.G ${ }^{\circ}$ 2015. This is an open-access article distributed under the terms of the Creative Commons Attribution License, which permits unrestricted use, distribution and reproduction in any medium, provided the original author and source are credited.

The cancer onus has been heightening over the last decades. Noteworthy is the prevalence among men in reproductive age, especially in children and adolescents. The actual improvement in the prognosis and treatment of cancer enables patients to prospect a long-term survival, which is contributing for an increase in infertility in patients that previously had cancer [1]. The concern with the patients' life quality with regard to their fertility preservation is under discussion and has been qualified as a priority topic in the American Society of Clinical Oncology (ASCO) recommendations [2] and in the American Society for Reproductive Medicine (ASRM) ethics committee opinions [3]. Both societies have thus recommended fertility preservation in patients facing gonadotoxic therapies as early as possible during treatment planning with a synergetic multidisciplinary approach between oncologists, reproductive physicians and psychologists.

Besides specific hormonal therapy used for gonad-protection, which is still not fully successful, no other pharmacological protocol is available. Therefore at present no medicine is available to effectively prevent cancer-induced infertility [4]. So far the most common approach to face this problem in post-pubertal males is sperm cryopreservation. Note that the harvest should be done prior to initiation of cancer treatment since the quality of samples and the sperm DNA integrity can be compromised after a single treatment session [5]. Even though these recommendations are followed, these are worthless for pre-pubertal boys because of their sexual immaturity. The seminiferous tubules of these children only contain spermatogonial stem cells (SSC). These SSC are able to yield the production of sperm, but before puberty they will not start their function [6]. Hence, for these patients the only option is to preserve these SSC.

Some centres through 'Oncofertility programs' have already started collecting and freezing SSC to preserve male human fertility [7]. In fact, studies in humans have proved that SSC can be cryopreserved either in a testicular tissue fragment [8] or in a cell suspension $[9,10]$. But, at this time, these programs can only be seen as the adoption of a preventive measure as the future use of these cells is still uncertain.

Although methods for grafting [11], infusion [12] and in vitro differentiation $[13,14]$ of testicular SSC are being developed and proved already to be efficient and enlightening, using animal models of transplantation $[15,16]$ and in vitro differentiation [17], much is still to be done in humans.

In humans, several technical obstacles have to be overcome, as there are two distinct populations of spermatogonia, A-dark and A-pale. These have to be clearly identified and separated since they might exhibit a heterogeneous molecular phenotype [18], and functional roles. Investigators will have to determine which type of spermatogonia contribute to sperm production under normal physiological circumstances, which type of spermatogonia replenishes the SSC pool and thus which is talented to repopulate the germinal epithelium after the gonadotoxic insult [19].

Independently of the experimental or investigational stage of these procedures, the cryopreservation programmes have already been initiated in some worldwide centres and thus some important issues must be addressed when cryopreserving SSC for future fertility restore. First, procedures should be under strict ethical, regulatory and legal controls. Second, patients must be informed of their possible future infertile status. Besides being counseled to cryopreserve SSC for their best interest, they have to be informed that this approach is still investigational. Third, that there is the eminent risk of malignant testicular contamination $[20,21]$. Regarding malignant contamination, this problem is being solved by selection protocols to isolate SSC free of contaminating patient's cancer cells and by using in vitro differentiation of patient's SSC before or after cryopreservation. Fourth, as children have 
small testis, there will be a limited amount of tissue recovered by testicular biopsy for SSC isolation and tissue grafting. In fact, the amount of tissue recovered at the biopsy should not compromise the future capability of testis to induce hormonal synthesis, necessary for the normal development of male characteristics and for the resume of the natural spermatogenesis process [22].

If at the early stages this subject was controversial, nowadays it is a well-accepted and safe procedure, and physicians have full responsibility to inform patients and their parents about the fertility preservation option in order to offer children the chance of becoming fathers in the future. Additionally, SSC isolation, purification and cryopreservation can also be extended to men that have already initiated cancer therapy and that have not cryopreserved sperm before treatments. Although a National Public Bank should be offered to oncologic patients independently of their social and economic resources, development of Private Banks will also be necessary.

\section{Acknowledgements}

UMIB (Pest-OE/SAU/UI0215/2014), CICS (Pest-C/SAU/ UI0709/2014) and MG Alves (SFRH/BPD/80451/2011) were funded by National Funds through FCT-Foundation for Science and Technology co-funded by Fundo Europeu de Desenvolvimento Regional - FEDER via Programa Operacional Factores de Competitividade - COMPETE/QREN, FSE and POPH funds.

\section{References}

[1]. Meistrich ML (2013) Effects of chemotherapy and radiotherapy on spermatogenesis in humans. Fertility and Sterility 100(5): 1180-6.

[2]. Lee SJ, Schover LR, Partridge AH, Patrizio P, Wallace WH, et al. (2006) American Society of Clinical Oncology recommendations on fertility preservation in cancer patients. J Clin Oncol 24(18): 2917-31.

[3]. Ethics Committee of American Society for Reproductive Medicine (2013) Fertility preservation and reproduction in patients facing gonadotoxic therapies: a committee opinion 100(5): 1224-31.

[4]. Magelssen H, Brydoy M, Fossa SD (2006) The effects of cancer and cancer treatments on male reproductive function. Nature Clinical Practice Urology 3(6): 312-22.

[5]. Trottmann M, Becker AJ, Stadler T, Straub J, Soljanik I, et al. (2007) Semen quality in men with malignant diseases before and after therapy and the role of cryopreservation. European Urology 52(2): 355-67.

[6]. Rey R (1999) Theprepubertal testis: a quiescent or a silently active organ? Histology and Histopathology 14(3): 991-1000.

[7]. McCook A (2013) A future, on ice. Nature Medicine 19: 958-61.

[8]. Baert Y, Goossens E, van Saen D, Ning L, Veld P, et al. (2012) Orthotopic grafting of cryopreserved prepubertal testicular tissue: in search of a simple yet effective cryopreservation protocol. Fertility and Sterility 97(5): 1152-57.

[9]. Sá R, Cremades N, Malheiro I, Sousa M (2012) Cryopreservation of human testicular diploid germ cell suspensions. Andrologia 44(6): 366-72.

[10]. Poels J, Van Langendonckt A, Many MC, Wese FX, Wyns C (2013) Vitrification preserves proliferation capacity in human spermatogonia. Human Reproduction 28(3): 578-89.

[11]. Goossens E, Van Saen D, Tournaye H (2013) Spermatogonial stem cell preservation and transplantation: from research to clinic. Human Reproduction 28(4): 897-907.

[12]. Ning L, Meng J, Goossens E, Lahoutte T, Marichal M, et al. (2012) In search of an efficient injection technique for future clinical application of spermatogonial stem cell transplantation: infusion of contrast dyes in isolated cadaveric human testes. Fertility and Sterility 98(6): 1443-48.

[13]. Sá R, Neves R, Fernandes S, Alves C, Carvalho F, et al. (2008) Cytological and expression studies and quantitative analysis of the temporal and stage-specific effects of follicle-stimulating hormone and testosterone during cocultures of the normal human seminiferous epithelium. Biology of Reproduction 79(5): 962-75.

[14]. Sadri-Ardekani H, Mizrak SC, van Daalen SK, Korver CM, Roepers-Gajadien HL, et al. (2009) Propagation of human spermatogonial stem cells in vitro. JAMA 302(19): 2127-34.

[15]. Brinster RL, Zimmermann JW (1994) Spermatogenesis following male germ-cell transplantation. Proccedings of the National Academy of Science USA 91(24): 11298-302.

[16]. Hermann BP, Sukhwani M, Winkler F, Pascarella JN, Peters KA, et al. (2012) Spermatogonial stem cell transplantation into rhesus testes regenerates spermatogenesis producing functional sperm. Cell Stem Cell 11(5): 715-26.

[17]. Sato T, Katagiri K, Kubota Y, Ogawa T (2013) In vitro sperm production from mouse spermatogonial stem cell lines using an organ culture method. Nature Protocols 8(11): 2098-104.

[18]. Sá R, Miranda C, Carvalho F, Barros A, Sousa M (2013) Expression of stem cell markers: OCT4, KIT, ITGA6, and ITGB1 in the male germinal epithelium. Systems Biology in Reproductive Medicine 59(5): 233-43.

[19]. Hermann BP, Sukhwani M, Hansel MC, Orwig KE (2010) Spermatogonial stem cells in higher primates: are there diferences from those in rodents? Reproduction 139(3): 479-93.

[20]. Jahnukainen K, Hou M, Petersen C, Setchell B, Söder O (2001) Intratesticular transplantation of testicular cells from leukemic rats causes transmission of leukemia. Cancer Research 61(2): 706-10.

[21]. Dovey SL, Valli H, Hermann BP, Sukhwani M, Donohue J, et al. (2013) Eliminating malignant contamination from therapeutic human spermatogonial stem cells. The Journal of clinical investigation 123(4): 1833-43.

[22]. Wallace WH, Anderson RA, Irvine DS (2005) Fertility preservation for young patients with cancer: who is at risk and what can be offered? Lancet Oncology 6(4): 209-18. 